\section{Effectivity of convex triangular and rectangular cross section instruments on decreasing the amount of root canal enterococcus faecalis bacteria colonies}

\author{
Meilina Goenawan, , Juni J. Nugroho, Christine A. Rovani, Aries C. Trilaksana,
}

\title{
Abstract
}

Objective: This study aims to evaluate effective difference between convex triangular and rectangular cross section rotary instruments on root canal with Enterococcus faecalis (E. faecalis) colonies.

Material and Methods: Samples of mandibular premolar teeth with one narrow and straight root canal were divided into 3 groups: instrumented with convex triangular cross section rotary instruments, rectangular cross section rotary instruments, and convex triangular cross section manual instruments. Each group consisted of nine samples. Standardized teeth length, instrumented to \#15 K-file and sterilized. E. faecalis suspension in BHIB was standardized and then 27 root canals were contaminated. Root canals were incubated for 21 days. Every 48 hours root canals were added with BHIB. Initial samples were collected, plated in agar culture medium and incubated for bacterial count and then bacterial count was performed again. Data were collected and analyzed using Paired T-test and ANOVA test.

Results: This indicates that there is a significant difference of the average number in colonies of $\mathrm{E}$. faecalis before and after the instrumentation on the utilization of the rotary instrument in cross section of rectangular, convex triangular, and cross section manual of convex triangular.

Conclusion: Showed there are significant differences on E. faecalis colonies amount before and after all instruments that was used and bacterial reduction amount in root canals were greater on convex triangular cross section instruments than on rectangular cross section instruments even though there was no significant difference.

Keywords: Rectangular cross section instrument, Convex triangular cross section instrument, E. faecalis bacteria colonies amount Cite this Article: Goenawan M, Nugroho JJ, Rovani CA, Trilaksana AC, Natsir N, Sumidarti A. 2016. Effectivity of convex triangular and rectangular cross section instruments on decreasing the amount of root canal enterococcus faecalis bacteria colonies. Journal of Dentomaxillofacial Science 1(2): 113-117. D0I:10.15562/jdmfs.v1i2.9

Department of Conservative Dentistry, Faculty of Dentistry, Hasanuddin University, Makassar, Indonesia

\section{*Correspondence to:}

Meilina Goenawan, Faculty of

Dentistry, Hasanuddin University mei_goenawan@yahoo.com

Received 16 March 2016 Revised 15 August 2016 Accepted 17 August 2016 Available online 31 August 2016

\section{Introduction}

Chemo-mechanical instrumentation of tooth root canal through a combination of mechanical instrumentation and irrigation of root canals is an important step in root canal disinfection. In the study conducted by Hulsmann ${ }^{1}$ it was shown that the mechanical instrumentation with sterile saline irrigation materials were able to reduce the number of bacterial colonies in the root canal significantly, even though it cannot totally inhibit bacteria in the root canal. Mechanical instrumentation of the root canal can be performed using manual instruments and instruments driven by the engine (rotary)., ${ }^{2,3}$

Protaper Universal files is one of NiTi root canal instruments that have some design characteristics such as the cross section of convex triangular, non-cutting tip, varying helicoidal angles and multiple and progressive taper. ProTaper Universal files come in two forms, namely manual and rotary. In Protaper Universal files, SX is designed to widen the root canal, S1 to apply on the one-third coronal root canal, S2 instruments to on apply the middle third, F1 and F2 instruments to largely widen the apical third and middle third root channel.
Protaper Universal rotary files are used at a speed of 150-300 rpm and a torque of 3-4 N.cm (file S1 and Sx), speed of 150-300 rpm and a torque of $1-1.5$ N.cm (file S2), speed of 150-300 rpm and a torque of 1.5-2 N.cm (file F1) and the speed of 150-300 rpm and a torque of 2-3 N.cm (file F2, F3, F4 and F5). ${ }^{2,4}$

Protaper next file has progressive properties like a taper design in the apical region and taper, which is downward to the corona with a rectangular-shaped cross section, which is symmetrical on both sides with an offset from the central axis of rotation that enable it to produce an asymmetrical rotational movement. protaper next is used at a speed of 300 rpm with torque from 2 to 5.2 N.cm. Asymmetric rotational movements make an instrument move like a phenomenon, which is called the rotational precision or swagger. Another advantage of the protaper next system is that this instrument is made of M-Wire and not of traditional alloy NiTi. the M-Wire alloy can reduce cyclic fatigue up to $400 \%$ compared to other instruments that are made of conventional alloy $\mathrm{NiTi}$. This allows the instrument 
to be more flexible, improve security and prevent fractures of instruments. In addition, protaper next is also a shorter handle instrument. Handle of protaper universal is $13 \mathrm{~mm}$, while the handle of protaper next has a length of $11 \mathrm{~mm}$. These changes facilitate access to areas that are difficult to be explored..$^{5-8}$

At the stage of the tooth root canal, besides mechanical instrumentation, root canal irrigation was also conducted. The ideal irrigation solution should be able to kill bacteria, dissolve necrotic tissue, lubricate the root canal, remove the smear layer and not irritate healthy tissue. Although there are currently many types of solutions, irrigates such as chlorhexidine (CHX), Iodine Potassium Iodide (IKI), Mixture of Tetracycline, Acid and Detergent (MTAD) and Ethylene diamine Tetra-Acetic Acid (EDTA), sodium hypochlorite $(\mathrm{NaOCl})$ is still a solution which is most frequently used for irrigation. Concentration of $\mathrm{NaOCl}$ used in root canal treatment varies between $0.5 \%$ and $5.25 \%$. Higher concentrations have the ability to dissolve tissue and better antimicrobial effect. However, higher concentrations also have a higher risk of toxicity to tissues. ${ }^{9}$

Enterococcus faecalis (E. faecalis) is grampositive cocci bacteria, anaerobic, facultative, fermentative, non-sporadic bacteria. E. faecalis is an ovoid-shaped bacterium with $0.5-1 \mu \mathrm{m}$ diameter. E. faecalis has some special characteristics that allow them to survive in conditions that are usually lethal for other microorganisms. This is caused by E. faecalis that can attach to the root canal walls, accumulate and forme a biofilm that allows the bacteria 1.000 times more resistant to phagocytosis, antibody and antimicrobial agent compared to an organism that does not produce any bio-film.

E. faecalis is often regarded as the main cause of failure of root canal treatment because it secretes gelatinase-like proteases and serine proteases. Gelatinase contributes to bone resorption and degradation of the organic matrix of dentin so that it plays an important role in the pathogenesis of periapical inflammation. ${ }^{10-13}$

\section{Material and Methods}

Twenty-seven samples of mandibular premolar teeth that have met the inclusion criteria were decoronated at the cemento-enamel junction (CEJ). Root length is standardized to $14 \mathrm{~mm}$ and the tooth root instrumented next to K-file \#15 with a working length of $13 \mathrm{~mm}$. The apex was coated with resin composite and the external surface of the tooth root was coated with dental epoxy resin. The root is then planted in a container by using acrylic resin and sterilized using an autoclave.
Root canal contaminated with a suspension of $\mathrm{E}$. faecalis in Brain-Heart Infusion Broth (BHIB) was standardized on a scale of McFarland 0.5 using a syringe and irrigation needle. Every 48 hours, BHIB was added. The root canal was incubated at $37^{\circ} \mathrm{C}$ for 21 days. After the incubation period, the root canal was filled with phosphate buffer solution (BPS). The first sample is collected using three sterile paper points \#15, each was inserted for a minute. Paper point was then put into a test tube containing $500 \mu \mathrm{l}$ of peptone water. The sample is then grown on agar culture medium using $10 \mathrm{ml}$ calibrated loop and incubated at $37^{\circ} \mathrm{C}$ for 24 hours. The bacterial count is measured in Colony-Forming Units (CFUs)/ $\mathrm{ml}$. The incubated sample is then divided into three test groups, namely:

- Group 1: Instrumented with convex triangular cross section rotary instruments. This instrumentation is conducted based on the working length, which is $13 \mathrm{~mm}$ from S1 file (with a speed of $150 \mathrm{rpm}$ and torque $3 \mathrm{~N} . \mathrm{cm}$ ), S2 (with a speed of $150 \mathrm{rpm}$ and torque 1 N.cm), F1, F2 and F3 (with a speed of $150 \mathrm{rpm}$ and torque $2 \mathrm{~N} . \mathrm{cm}$ ). Irrigation is done on each turn of the tool as much as $2 \mathrm{ml}$ of $0.5 \% \mathrm{NaOCl}$ irrigation using irrigation needle, which is placed $2 \mathrm{~mm}$ of working length and it is rinsed with $5 \mathrm{ml}$ sterile distilled water after the root instrumentation is complete.

- Group 2: Instrumented sample with rectangular cross section rotary instruments. This instrumentation is based on the working length, which is $13 \mathrm{~mm}$ from the file $\mathrm{X} 1, \mathrm{X} 2$ and X3 (with a speed of $300 \mathrm{rpm}$ and torque 2 N.cm). Irrigation is done on each turn of the tool as much as $2 \mathrm{ml}$ of $0.5 \% \mathrm{NaOCl}$ irrigation using irrigation needle, which is placed at 2 $\mathrm{mm}$ of working length and it was rinsed with $5 \mathrm{ml}$ sterile distilled water after the root instrumentation is complete.

- Group 3: Instrumented sample with manual instruments convex triangular cross section. This instrumentation is done based on the working length, which is $13 \mathrm{~mm}$ from the file $\mathrm{S} 1, \mathrm{~S} 2, \mathrm{~F} 1, \mathrm{~F} 2$ and F3. Irrigation is done on each turn of the tool as much as $2 \mathrm{~mL}$ of $0.5 \%$ $\mathrm{NaOCl}$ irrigation using irrigation needle, which is placed at $2 \mathrm{~mm}$ of working length and it is rinsed with $5 \mathrm{ml}$ sterile distilled water after root instrumentation is complete.

After the instrumentation was finished, root canal is refilled with BPS and samples were collected using three sterile paper points \#15 and each were inserted for 1 minute. Paper point was then put into a test tube containing $500 \mu \mathrm{l}$ of peptone water. The 
samples were then grown on agar culture medium using $10 \mathrm{ml}$ calibrated loop and incubated at $37^{\circ} \mathrm{C}$ for 24 hours. The bacterial count is measured in colony-forming units (CFUs)/ml.

\section{Results}

Table 1 shows the distribution and the difference of average number in bacterial colonies of E. faecalis (CFUs/mL) in root canal before and after the instrumentation. According to the result of the statistical test, paired sample t-test, we finally discover the value of $\mathrm{p}: 0.000(\mathrm{p}<0.05)$ in three of the instrument groups. This result indicates that there is a significant difference of the average number in colonies of E. faecalis before and after the instrumentation on the utilization of the rotary instrument in cross section of rectangular, convex triangular and cross section manual of convex triangular.

Table 2 exhibits about the difference of the average reduction from the number of bacterial colonies of $\mathrm{E}$. faecalis between the rotary instrument in

Table 1 The difference in the average number in bacterial colonies of $\mathrm{E}$. faecalis (CFUs/ml) in the root canal before and after the instrumentation

\begin{tabular}{|c|c|c|c|c|}
\hline \multirow{2}{*}{ Instruments } & \multirow{2}{*}{$\begin{array}{c}n \\
(\%)\end{array}$} & $\begin{array}{c}\text { Before } \\
\text { instrumentation }\end{array}$ & $\begin{array}{c}\text { After } \\
\text { instrumentation }\end{array}$ & \multirow[b]{2}{*}{ p-value } \\
\hline & & Mean \pm SD & Mean \pm SD & \\
\hline $\begin{array}{l}\text { The rotary of } \\
\text { rectangular }\end{array}$ & $9(33.3)$ & $51383.33 \pm 3851.45^{a}$ & $400.00 \pm 236.64^{\mathrm{a}}$ & $0.000^{*}$ \\
\hline $\begin{array}{l}\text { The rotary } \\
\text { of convex } \\
\text { triangular }\end{array}$ & $9(33.3)$ & $52416.67 \pm 3697.25^{a}$ & $400.00 \pm 141.42^{\mathrm{a}}$ & $0.000^{*}$ \\
\hline $\begin{array}{l}\text { The manual } \\
\text { of convex } \\
\text { triangular }\end{array}$ & $9(33.3)$ & $52566.67 \pm 3413.89^{a}$ & $416.67 \pm 231.66^{a}$ & $0.000^{*}$ \\
\hline
\end{tabular}

Note: a : Data normality test: Shapiro-Wilk test; ${ }^{*} \mathrm{p}>0.05$; Normal data distribution. ${ }^{*}$ : Paired Sample t-test: $\mathrm{p}<0.05$; significant.

Table 2 The difference of average reduction from a number of bacterial colonies of E. faecalis between the rotary instrument in cross section of rectangular, convex triangular and cross section manual of convex triangular

\begin{tabular}{lcc} 
& $\begin{array}{c}\text { The number reduction from bacterial } \\
\text { colonies of } \text { E. faecalis (CFUs/mL) }\end{array}$ & p-value \\
\cline { 2 - 3 } Instruments & Mean \pm SD & \\
\hline $\begin{array}{l}\text { The rotary of rectangular } \\
\text { The rotary of convex }\end{array}$ & $50983.33 \pm 3631.75^{\mathrm{a}}$ & $0.821^{*}$ \\
triangular & $52016.67 \pm 3581.29^{\mathrm{a}}$ & \\
$\begin{array}{l}\text { The manual of convex } \\
\text { triangular }\end{array}$ & $52150.00 \pm 3262.36^{\mathrm{a}}$ & \\
\hline
\end{tabular}

Note: a: Data normality test: Shapiro-Wilk test; $\mathrm{p}>0.05$; Normal data distribution. ${ }^{*}$ : Anova One-Way test: $\mathrm{p}>0.05$; significant. cross section of rectangular, convex triangular and cross section manual of convex triangular. Based on the result of statistical test, Anova, we obtain the value of $p: 0.821(p>0.05)$ which means that there is a significant difference of the average reduction from a number of bacterial colonies of $\mathrm{E}$. faecalis between the rotary instrument in cross section of rectangular, convex triangular and cross section manual of convex triangular.

\section{Discussion}

Root canal instrumentation is essential in root canal treatment, which can be divided into two parts that consist of mechanical instrumentation and irrigation of the root canal. The purpose of mechanical instrumentation is to widen the canal, to decrease the number of bacterial colonies on the surface and within the dentinal tubules of the root canal by cutting the dentin of root canal and facilitating the action of disinfection of irrigation solution. Today, the cross section instruments of convex triangular with all the contact side of the canal wall at the same time is one of the instruments often applied. Recently, we are commercially introduced the rectangular cross section instruments. One of the properties of this instrument design is a rectangular-shaped cross section, which is symmetrical on both sides with an offset from the central axis of rotation (except for the last $3 \mathrm{~mm}$ of such instruments, D0-D3), so it can create an asymmetrical rotation movement. The asymmetrical rotational movements establish an instrument to have a rotational phenomenon called precession or swagger. According to Van der Vyver et al. ${ }^{6}$ the characteristic of this design has several advantages, one of them is each of the instrument is able to trim by envelope motion which is wider (the larger size of the root canal instrumentation) than the same instrument that has the symmetrical mass and the axis of rotation. Thus, number of instruments used by clinicians to the fewer root canal instrumentation with the shape and the taper are adequate for optimal irrigation and obturation. ${ }^{14}$

On the phase of root canal instrumentation besides mechanical instrumentation, irrigation lateness is required to eliminate the residual microbes, which exist in the root canal. Although there are currently many types of irrigation solution, sodium hypochlorite $(\mathrm{NaOCl})$ is still the most frequently used irrigation solution in this field. $\mathrm{NaOCl} 0.5 \%$ utilized in this research has the lubricant effect. The concentration of $\mathrm{NaOCl}$ used in this research 
the instrument to reduce the bacterial colonies on the surface and within the dentinal tubules of the root canal by cutting the dentin of root canal can be seen. ${ }^{15-17}$

Plate culture technique is a method, which is often used in research concerning the bacterial colonies. Research conducted by Nabeshima et al. ${ }^{18}$ discovered that there were many bacteria, which could be detected by using this method. This theory is parallel with the research conducted by Alves et al. ${ }^{19}$ who obtained similar results by using the molecular polymerase chain reaction (PCR) and plate culture techniques. That biofilm can be observed by using scanning electron microscopy, but Nabeshima et al. ${ }^{18}$ concluded that this method did not guarantee the observation of the entire depth on the biofilm structure and viability. The plate culture techniques to assess the reduction in the number of bacterial colonies in the root canal before and after the instrumentation. ${ }^{19}$

Table 1 reveals the distribution and the difference of average number in bacterial colonies of $\mathrm{E}$. faecalis $(\mathrm{CFUs} / \mathrm{mL})$ in root canal before and after the instrumentation. According to the result of statistical test, paired sample t-test, we finally discover about the value of $\mathrm{p}: 0.000(\mathrm{p}<0.05)$ in three of the instrument groups. This result indicates that there is a significant difference of the average number in colonies of $\mathrm{E}$. faecalis before and after the instrumentation on usage of the rotary instrument in cross section of rectangular, convex triangular and cross section manual of convex triangular. This result is consistent with the research conducted by Nabeshima et al. ${ }^{18}$ which stated that all root canal instrumentation techniques used in their research significantly reduced the numbers of bacterial colonies in root canals more than $92 \%$. This is also in line with the literature, which indicates that the phase of root canal instrumentation system in endodontic treatment is the most important step to eliminate or to control the infection in dentin. ${ }^{20}$

Table 2 represents the difference of average reduction from the number of bacterial colonies of E. faecalis between the rotary instrument in cross section of rectangular, convex triangular and cross section manual of convex triangular. Based on the result of statistical test, Anova, we obtain the value of $\mathrm{p}: 0.821(\mathrm{p}>0.05)$, which means that there is a significant difference of average reduction from a number of bacterial colonies of $\mathrm{E}$. faecalis between the rotary instrument in cross section of rectangular, convex triangular and cross section manual of convex triangular. In this research, there are no significant difference in the average reduction from the number of bacterial colonies of $\mathrm{E}$. faecalis among all the investigated instruments caused by calculation of the number of bacterial colonies in this research, which uses the dilution $10 \mu \mathrm{l}$, so that bacteria cannot be calculated in the unit number.

The least decline in this research is figured out in the clusters of rectangular cross section instrument, which only amounts to $50983.33 \mathrm{CFUs} / \mathrm{ml}$. It can be due to the form of rectangular instrument, which is symmetrical on both sides of those with an offset from the central axis of rotation to produce an asymmetrical rotational movement, so there are only two cut points, which is related to the root canal wall that causes less clipped amount of the dentin of root canal.

After the research was performed, the effectiveness of the convex triangular and rectangular cross section instrument over the degradation in the number of bacterial colonies of $\mathrm{E}$. faecalis in the root canal became apparent. This concluded that mechanical instruments using the rotary file in cross section of rectangular, convex triangular and cross section manual of convex triangular effectively reduced the number of bacterial colonies in the root canal. Moreover, the amount of reduction of bacterial colonies in the root canal on the cross section instrument of convex triangular is larger than the rectangular cross section instrument even though it is not significantly different. Otherwise, on the cross section instruments of convex triangular, the shape of this instrument creates a symmetrical rotational movement. This shape will constantly make the files in contact with the canal wall on three points during the rotation. The smaller the root canal instrument, the lower is the ability to reduce the level of infection in the root canal. The broader instrument will reach the most irregular anatomical area and eliminate the substantial amount of bacterial cells in the root canal. Meanwhile, the wider instrument has better irrigation solution. Therefore, the usage of rectangular cross section instruments shall be used in the cases of bacterial infections, which may not entered deep into the dentinal tubules but still the instrument can cut the less dentin root canal than the cross section instrument of convex triangular.

\section{Conclusion}

There are significant differences on the amount of E. faecalis colonies before and after the preparation of all instruments that was used and bacterial reduction amount in root canals were greater on 
techniques/methods of different assessments and the research, which adopt the in vivo design.

\section{Conflict of Interest}

The authors report no conflict of interest.

\section{References}

1. Hulsmann M, Peters OA, Dummer PMH. Mechanical preparation of root canals: shaping goals, techniques and means. Endodontic Topics 2005;10: 30-76.

2. Young GR, Parashos P, Messer HH. The principles of techniques for cleaning root canals. Aust Dent J Supp 2007;52: 52-63.

3. Parashos P, Messer HH. The diffusion of innovation in dentistry: a review using nickel-titanium technology. Oral Surg Oral Med Oral Pathol Oral radiol Endod 2006;101: 395-401.

4. Arias A, Singh R, Peters OA. Torque and force induced by protaper universal and protaper next during shaping of large and small root canals in extracted teeth. JOE 2014;40: $1-4$.

5. Wu H, Peng C, Bai Y, et al. Shaping ability of protaper universal and protaper next in simulated 1-shaped and s-shaped root canals. BMC Oral health 2015;15: 1-7.

6. Van-der VPJ, Scianamblo MJ. Clinical guidelines for the use of protaper next instruments (part I). Endod Practice 2013;16: 33-40.

7. Van-der Vyver PJ, Scianamblo MJ. Clinical guidelines for the use of protaper next instruments (part II). Endod Practice 2014.

8. Johnson E, Lloyd A, Kuttler S, et al. Comparison between a novel nickel titanium and 508 nitinol on the cyclic fatigue life of Profile 25/.04 NiTi instruments. J Endod 2008;4: 1406-1409.

9. Torabinejad M, Rivera EM. Cleaning and shaping. In Torabinejad M, Walton RE, editors. Principles and practice of endodontics. 4th ed. St. Louis: Saunders Elsevier; 2009. p. 206-207.

10. Patidar RK, Gupta MK, Singh V. Phenotypic detection of virulence traits and antibiotic susceptibility of endodontic enterococcus faecalis isolates. American J Microbiolo Res 2013;1: 4-9.

11. Mallick R, Mohanty S, Behera S, et al. Enterococcus faecalis: a resistant microbe in endodontics. Int J Contemp Dent Med Rev 2014: 1-2.

12. Denotti G, Piga R, Montaldo C, et al. In vitro evaluation of enterococcus faecalis adhesion on various endodontic medicaments. The Open Dentistry Journal 2009;3: $120-124$.

13. Suchitra U, Kundabala M. Enterococcus faecalis: an endodontic pathogen. Available from: medind.nic.in/eaa/t06/ i2/eaat06i2p11.pdf

14. Vazhiyodan A, Rao SR, Padmanabhan P, et al. Comparison of root canal cleaning ability of protaper and liberator rotary niti instrument systems-a sem study. IJCD 2011;2: 95-99.

15. Mohammadi Z. Sodium hypochlorite in endodontics: an update review. Int Dent J 2008;58: 329-341.

16. Gomes BPFA, Ferraz CCR, Vianna MEVB, et al. In vitro antimicrobial activity of several concentrations of sodium hypochlorite and chlorhexidine gluconate in the elimination of Enterococcus faecalis. Int Endod J 2001;34: 24-28.

17. Mistry KS, Shah S. Review on common root canal irrig ants. J Dent Sci 2: 27-31.

18. Nabeshima CK, Caballero-Flores H, Cai S, et al. Bacterial removal promoted by 2 single-file systems: wave one and one shape. JOE 2014;40: 1995-1998

19. Alves FRF, Rôćas IN, Almeida BM, et al. Quantitative molecular and culture analyses of bacterial elimination in oval-shaped root canals by a single-file instrumentation technique. Int Endod J 2012;45: 871-877.

20. Haapasalo M, Endal U, Zandi H, et al. Eradication of end- odontic infection by instrumentation and irrigation solutions. Endod Topics 2005;10: 77-102.

21. Guelzow A, Stamm O, Martus P, et al. Comparative study of six rotary nickel-titanium systems and hand instrumentation for root canal preparation. Int Endod J 2005;38: 743-752.

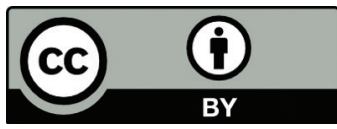

This work is licensed under a Creative Commons Attribution 